\title{
Epidemiological and histological profile of stomach adenocarcinomas between 1997-2006 and between 2007- 2016
}

\author{
Nogueira EP*, Brito PHF, Castro OAP, Ganem LM, Fukuhara DK, Cordts RM, Marinho MS, Claro LCL, Freitas JrWR, Ilias EJ, Malheiros \\ $\mathrm{CA}$ and Kassab P \\ Department of Surgery, Santa Casa of Sao Paulo Medical School, Sao Paulo, Brazil
}

\section{Introduction}

Gastric adenocarcinoma is the fourth most common type of cancer and the second leading cause of cancer death in the world, second only to lung cancer [1-3]. Although both its incidence and mortality have fallen dramatically in recent decades, it remains a relevant health issue, as its decrease is low in Asian countries and, in addition, it remains with a high mortality rate in western countries $[4,5]$. In this scenario, it is known that demographic trends vary according to the location of the tumor and its histological classification [1]

There are reports of changes in location with an increased incidence of proximal neoplasms, especially of cardia cancer in western countries. Another aspect is that in those same countries there seems to have been a decrease in the intestinal type. Their relative frequencies are $54 \%$ for the intestinal one, $32 \%$ for the diffuse and $15 \%$ for the indeterminate $[6,7]$. In this context, there are indicators that diffuse adenocarcinomas most commonly affect women and younger people $[6,8,9]$ while intestinal types are more associated with intestinal metaplasia and Helicobacter pylori infections $[6,10,11]$.

Apparently, there was also a global decrease in mortality related to higher rates of early diagnosis with an increase in cases at earlier stages. In addition, the increased availability of effective complementary treatments also increased survival.

In order to assess whether the changes observed worldwide occurred in our country, we conducted a study in our series.

\section{Methods}

A retrospective analysis of data acquired in a prospective data collection registration protocol was performed. Epidemiological, clinical, surgical and oncological data of all patients (submitted to resection or not) were analyzed and compared.

Inclusion criteria: all patients with stomach cancer treated at the service from 1997 to 2018. Regarding the histological type of Laurén, it was classified as: diffuse, intestinal, adenocarcinoma (in cases where this data was not available). The definition of mixed was avoided as much as many cases were analyzed many years ago and not all slides were reviewed. Even so, some cases were classified as mixed, respecting the pathologist's report. Histopathological subclassification referred to histological subtypes, namely: adenocarcinoma (when there was no subclassification), well differentiated, moderately differentiated, poorly differentiated, signet ring, little differentiated with signet ring and small cell carcinoma (not included in the Laurén classification).
Global mortality included patients who died from cancer or not, and postoperative deaths (30 days) were excluded. No period was defined maximum survival and the minimum period was one year for patients operated until 2018. In 877 patients, follow-up was at least 5 years, reaching up to 20 years.

The procedures were classified as: "inoperable", mucosectomy, subtotal gastrectomy, total gastrectomy, proximal gastrectomy and wedge resection (absolute exception for adenocarcinomas). The inoperable ones included a series of conditions: inextirpability, carcinomatosis, metastatic disease, poor general condition or patient refusal.

For staging, the 7th edition of the Classification of Malignant Tumors of the International Union Against Cancer (UICC) was used [12].

The tumor sites were based on the Japanese Classification of gastric carcinomas, [12] and are classified into three basic regions: $\mathrm{U}$ (upper third), M (middle third) and L (lower third); in cases of esophageal invasion, the letter $\mathrm{E}$ is placed and in the case of duodenal invasion, the letter D [13]. The site where most of the tumor is located was the one considered. Thus, neoplasms can be located in various places, for example: MLU - it is a tumor whose most part is located in the middle third, followed by the lower third and the smallest part is in the upper third, and so on. For tumors of the gastric esophageal junction, the word U was associated with the roman numbers II or III. The acronyms II or III refer to the Siewert classification for neoplasms of the gastric esophageal junction [14]. Finally, in neoplasms of the remaining stomach after previous gastrectomies, the site was defined only as a stump. In these cases, only patients previously operated on the stomach for benign disease and those operated for malignant disease more than 5 years after the previous gastrectomy were considered (thus excluding stump recurrences).

Exclusion criteria: patients with non-adenocarcinoma stomach cancer and patients with data not available.

The study did not involve any risk for patients and, at no time, there was or will be exposure of them.

${ }^{*}$ Correspondence to: Eliane Portela Nogueira, Department of Surgery, Santa Casa of Sao Paulo Medical School, Sao Paulo, Brazil, Tel: +5511991081551; E-mail: elianenogueiral@hotmail.com

Received: March 28, 2020; Accepted: April 17, 2020; Published: April 20, 2020 
For statistical analysis, the Mann-Whitney test was used to verify differences in age and survival time between the different study periods. The Chi-square test or Fisher's exact test was used to verify possible associations between the variables studied in the different study periods.

\section{Results}

Comparing the two periods studied, we could observe that there was no difference in the age range of patients in the periods studied, maintaining an average of 62 years in both periods. There was also no change in the distribution between the gender, with greater affection of the male sex (62.8\% in the first period and $61.8 \%$ in the second period). Data on histological types, global mortality, types of resection, depth (T), lymph node invasion, metastases, histological subclassification, location and stage, are shown in Tables 1-9.

\section{Discussion}

It is known that in developed countries the incidence of stomach cancer declined between the 1930s and 2000 [15]. The aspect observed in more developed countries did not have the same pattern in developing countries, where the reduction has been observed only more recently [16].
Traditionally, several studies have shown that the proportion of men affected is higher than women in the ratio of 4,6:1 [17]. This was mainly due to a higher prevalence of habits related to the causes of the disease among men, such as smoking and alcohol consumption. Although the incidence of adenocarcinoma has been decreasing over the decades in both sexes. This characteristic has been changing over the years, due to cultural changes, where women have acquired more and more habits and occupations more related to the causes of the disease [18]. We did not observe a decrease in the difference between men and women, perhaps due to the fact that female emancipation in our environment happened later, especially in socially disadvantaged groups where prejudice and discrimination against women are even more noticeable.

A lot is also discussed about the age and histological distribution. In general, in developed countries, the age range for the appearance of gastric adenocarcinoma is close to 70 years for intestinal type and around 65 years for diffuse type [5]. In our country, the age group was inferior, possibly related to factors such as more frequent chronic aggression to the mucosa since childhood and adolescence, less access to fresh fruits and vegetables, which are protective, higher incidence of $\mathrm{H}$. pylori infection and poor dietary education with ingestion of carcinogenic foods (example - meat from the sun a typical dried meat

Table 1. Histological type of Laurén

\begin{tabular}{|c|c|c|c|c|c|c|}
\hline \multirow{3}{*}{ Histological type } & \multicolumn{4}{|c|}{ Periods } & \multirow{2}{*}{\multicolumn{2}{|c|}{ Total }} \\
\hline & \multicolumn{2}{|c|}{$1997-2006$} & \multicolumn{2}{|c|}{$2007-2016$} & & \\
\hline & $\mathrm{N}$ & $\%$ & $\mathrm{~N}$ & $\%$ & $\mathrm{~N}$ & $\%$ \\
\hline Adenocarcinoma & 13 & 4.3 & 12 & 1.8 & 25 & 2.6 \\
\hline Diffuse & 186 & 62.5 & 418 & 63.8 & 604 & 63.4 \\
\hline Intestinal & 97 & 32.5 & 223 & 34.1 & 320 & 33.6 \\
\hline Mixed & 0 & 0.0 & 1 & 0.15 & 1 & 0.1 \\
\hline Others & 2 & 0.7 & 1 & 0.15 & 3 & 0.3 \\
\hline Total & 298 & 100.0 & $655^{*}$ & 100.0 & 953 & 100.0 \\
\hline
\end{tabular}

*15 with No histological data.

Fisher's exact test $\mathrm{p}=0.1161$ (N.S.)

Table 2. Global mortality except postoperative deaths

\begin{tabular}{|c|c|c|c|c|c|c|}
\hline \multirow{3}{*}{ Mortality } & \multicolumn{4}{|c|}{ Period } & \multirow{2}{*}{\multicolumn{2}{|c|}{ Total }} \\
\hline & \multicolumn{2}{|c|}{$1997-2006$} & \multicolumn{2}{|c|}{$2007-2016$} & & \\
\hline & $\mathrm{N}$ & $\%$ & $\mathrm{~N}$ & $\%$ & $\mathrm{~N}$ & $\%$ \\
\hline Yes & 193 & 68.7 & 316 & 52.0 & 509 & 57.3 \\
\hline No & 88 & 31.3 & 292 & 48.0 & 380 & 42.7 \\
\hline Total & $281^{*}$ & 100.0 & $608 * *$ & 100.0 & 889 & 100.0 \\
\hline
\end{tabular}

*1 without information on mortality and 16 deaths from surgical complications

**54 without information on mortality and 8 deaths from surgical complications

Chi-square test $\quad \mathrm{X}^{2}=21.925 \quad \mathrm{p}<0.0001 *$

Mortality in the period 1997-2006 $>2007-2016$

Table 3. Types of procedures

\begin{tabular}{|c|c|c|c|c|c|c|}
\hline \multirow{3}{*}{ Ressection } & \multicolumn{4}{|c|}{ Period } & \multirow{2}{*}{\multicolumn{2}{|c|}{ Total }} \\
\hline & \multicolumn{2}{|c|}{$1997-2006$} & \multicolumn{2}{|c|}{$2007-2016$} & & \\
\hline & $\mathrm{N}$ & $\%$ & $\mathrm{~N}$ & $\%$ & $\mathrm{~N}$ & $\%$ \\
\hline Inoperable & 92 & 30.9 & 210 & 31.3 & 302 & 31.2 \\
\hline Proximal & 1 & 0.4 & 4 & 0.6 & 5 & 0.6 \\
\hline Subtotal & 139 & 46.6 & 335 & 50.0 & 474 & 48.9 \\
\hline Total & 65 & 21.7 & 119 & 17.8 & 184 & 19.1 \\
\hline Wedge & 1 & 0.4 & 0 & 0.0 & 1 & 0.1 \\
\hline EMR & 0 & 0.0 & 2 & 0.3 & 2 & 0.2 \\
\hline Total & 298 & 100.0 & 670 & 670 & 968 & 100.0 \\
\hline
\end{tabular}

Fisher's exact test $\mathrm{p}=0.3386$ (N.S.)

$\mathrm{EMR}=$ Endoscopic mucosal resection 
Table 4. Depth (T)

\begin{tabular}{|c|c|c|c|c|c|c|}
\hline \multirow{3}{*}{ Stage $T$} & \multicolumn{4}{|c|}{ Period } & \multirow{2}{*}{\multicolumn{2}{|c|}{ Total }} \\
\hline & \multicolumn{2}{|c|}{$1997-2006$} & \multicolumn{2}{|c|}{$2007-2016$} & & \\
\hline & $\mathrm{N}$ & $\%$ & $\mathrm{~N}$ & $\%$ & $\mathrm{~N}$ & $\%$ \\
\hline $\mathbf{0}$ & 0 & 0.0 & 1 & 0.15 & 1 & 0.1 \\
\hline 1 & 42 & 14.1 & 102 & 15.2 & 144 & 14.9 \\
\hline 2 & 43 & 14.4 & 56 & 8.4 & 99 & 10.2 \\
\hline 3 & 6 & 2.0 & 86 & 12.8 & 92 & 9.5 \\
\hline $4 a$ & 108 & 36.2 & 204 & 30.4 & 312 & 32.2 \\
\hline $4 b$ & 49 & 16.4 & 72 & 10.7 & 121 & 12.5 \\
\hline $\mathbf{X}$ & 50 & 16.8 & 149 & 22.2 & 199 & 20.6 \\
\hline Total & 298 & 100.0 & 670 & 100.0 & 968 & 100.0 \\
\hline
\end{tabular}

Chi-square test $\quad \mathrm{X}^{2}=24.549$

Staging T $3<2007-2016$ period

$\mathrm{p}=0.0004^{*}$

$\mathrm{p}<0.0001^{*}$

Table 5. Lymph node invasion (N)

\begin{tabular}{|c|c|c|c|c|c|c|}
\hline \multirow{3}{*}{ Stage N } & \multicolumn{4}{|c|}{ Period } & \multirow{2}{*}{\multicolumn{2}{|c|}{ Total }} \\
\hline & \multicolumn{2}{|c|}{$1997-2006$} & \multicolumn{2}{|c|}{$2007-2016$} & & \\
\hline & $\mathrm{N}$ & $\%$ & $\mathrm{~N}$ & $\%$ & $\mathrm{~N}$ & $\%$ \\
\hline 0 & 88 & 29.5 & 193 & 28.8 & 281 & 29.0 \\
\hline 1 & 32 & 10.7 & 58 & 8.7 & 90 & 9.3 \\
\hline 2 & 41 & 13.8 & 123 & 18.4 & 164 & 17.0 \\
\hline 3 & 61 & 20.5 & 130 & 19.4 & 191 & 19.7 \\
\hline $\mathbf{X}$ & 76 & 25.5 & 166 & 24.8 & 242 & 25.0 \\
\hline Total & 298 & 100.0 & 670 & 100.0 & 968 & 100.0 \\
\hline
\end{tabular}

Chi-square test $\quad \mathrm{X}^{2}=3.854 \quad \mathrm{p}=0.4262$ (N.S.)

Table 6. Metastases (M)

\begin{tabular}{|c|c|c|c|c|c|c|}
\hline \multirow{3}{*}{ Stage M } & \multicolumn{4}{|c|}{ Period } & \multirow{2}{*}{\multicolumn{2}{|c|}{ Total }} \\
\hline & \multicolumn{2}{|c|}{$1997-2006$} & \multicolumn{2}{|c|}{$2007-2016$} & & \\
\hline & $\mathrm{N}$ & $\%$ & $\mathrm{~N}$ & $\%$ & $\mathrm{~N}$ & $\%$ \\
\hline $\mathbf{0}$ & 201 & 67.4 & 443 & 66.5 & 644 & 66.7 \\
\hline \multirow[t]{2}{*}{1} & 97 & 32.6 & 224 & 33.5 & 321 & 33.3 \\
\hline & 298 & 100.0 & $667^{*}$ & 100.0 & 965 & 100.0 \\
\hline
\end{tabular}

*3 without data

Chi-square test $\quad \mathrm{X}^{2}=0.099 \quad \mathrm{p}=0.8098$ (N.S.)

Table 7. Histopathological subclassification.

\begin{tabular}{|c|c|c|c|c|c|c|}
\hline \multirow{3}{*}{ Histopathology } & \multicolumn{4}{|c|}{ Period } & \multirow{2}{*}{\multicolumn{2}{|c|}{ Total }} \\
\hline & \multicolumn{2}{|c|}{$1997-2006$} & \multicolumn{2}{|c|}{$2007-2016$} & & \\
\hline & $\mathrm{N}$ & $\%$ & $\mathrm{~N}$ & $\%$ & $\mathrm{~N}$ & $\%$ \\
\hline Signet ring & 0 & 0.0 & 2 & 0.3 & 2 & 0.2 \\
\hline Moderately & 97 & 32.8 & 213 & 32.8 & 310 & 32.8 \\
\hline Adenocarcinoma & 11 & 3.7 & 14 & 2.2 & 25 & 2.6 \\
\hline Poorly differentiated & 61 & 20.6 & 158 & 24.3 & 219 & 23.2 \\
\hline Poorly differentiated signet ring & 115 & 38.8 & 215 & 33.1 & 330 & 34.9 \\
\hline Small cells & 0 & 0.0 & 1 & 0.15 & 1 & 0.1 \\
\hline Well differentiated & 10 & 3.4 & 46 & 7.1 & 56 & 5.9 \\
\hline Total & $294^{*}$ & 100.0 & $649 * *$ & 100.0 & 943 & 100.0 \\
\hline
\end{tabular}

*15 without data

**10 without data

Fisher's exact test $\quad \mathrm{p}=0.0851$ (N.S)

consumed in north and northeast regions of our country) [19]. In the data analyzed in this study, we noted that the age group was close to 60 years and that this pattern has not changed in the two decades analyzed, allowing us to think that the preventive and screening measures were ineffective in our country. We therefore see, still, relatively young patients affected by the disease.

Cislo, et al. [20] reported that the intestinal type corresponded to $54 \%$ of cases, being twice as frequent in men than in women, and located more in the antrum. On the other hand, they noted that the diffuse type, which corresponds to $32 \%$ of the cases, occurs with the same frequency in men and women, and the patients affected are on average, younger than the patients affected by the intestinal type.

Apparently in recent years, intestinal type rates have been decreasing, and this decrease is probably due to the drop in the prevalence of Helicobacter pylori infections and the change in alimentary patterns [21]. 
Table 8. Tumor site

\begin{tabular}{|c|c|c|c|c|c|c|}
\hline \multirow{3}{*}{ Tumor site } & \multicolumn{4}{|c|}{ Period } & \multirow{2}{*}{\multicolumn{2}{|c|}{ Total }} \\
\hline & \multicolumn{2}{|c|}{$1997-2006$} & \multicolumn{2}{|c|}{$2007-2016$} & & \\
\hline & $\mathrm{N}$ & $\%$ & $\mathrm{~N}$ & $\%$ & $\mathrm{~N}$ & $\%$ \\
\hline $\mathbf{L}$ & 93 & 31.2 & 220 & 33.3 & 313 & 32.7 \\
\hline LD & 26 & 8.7 & 20 & 3.0 & 46 & 4.8 \\
\hline LM & 37 & 12.4 & 76 & 11.5 & 113 & 11.8 \\
\hline LMD & 2 & 0.7 & 0 & 0.0 & 2 & 0.2 \\
\hline LMU & 9 & 3.0 & 12 & 1.8 & 21 & 2.2 \\
\hline M & 25 & 8.4 & 75 & 11.4 & 100 & 10.4 \\
\hline ML & 19 & 6.4 & 44 & 6.7 & 63 & 6.6 \\
\hline MLD & 1 & 0.3 & 1 & 0.15 & 2 & 0.2 \\
\hline MLU & 2 & 0.6 & 14 & 2.1 & 16 & 1.7 \\
\hline MU & 6 & 2.0 & 17 & 2.6 & 23 & 2.4 \\
\hline MUL & 7 & 2.3 & 15 & 2.3 & 22 & 2.3 \\
\hline STUMP & 15 & 5.0 & 39 & 5.9 & 54 & 5.6 \\
\hline $\mathbf{U}$ & 14 & 4.7 & 72 & 10.9 & 86 & 9.0 \\
\hline U CARDIAII & 7 & 2.4 & 6 & 0.9 & 13 & 1.4 \\
\hline U CARDIA III & 4 & 1.3 & 0 & 0.0 & 4 & 0.4 \\
\hline UE & 0 & 0.0 & 2 & 0.3 & 2 & 0.2 \\
\hline UM & 10 & 3.4 & 25 & 3.7 & 35 & 3.6 \\
\hline UML & 21 & 7.0 & 23 & 3.5 & 44 & 4.6 \\
\hline UMLD & 0 & 0.0 & 1 & 0.15 & 1 & 0.1 \\
\hline Total & 298 & 100.0 & $660 *$ & 100.0 & 958 & 100.0 \\
\hline
\end{tabular}

*10 without data

Chi-square test $\quad \mathrm{X}^{2}=55.556$

LD less present in 2007-2016

LMU less present in 2007-2016

U more present in 2007-2016

U Cardia II less present in 2007-2016

U Cardia III less present in 2007-2016

UML less present in 2007-2016

$$
\begin{gathered}
\mathrm{p}<0.0001^{*} \\
\mathrm{p}=0.0002^{*} \\
\mathrm{p}=0.0413 \\
\mathrm{p}=0.045 \\
\mathrm{p}=0.015 \\
\mathrm{p}=0.015 \\
\mathrm{p}=0.015
\end{gathered}
$$

\begin{tabular}{|c|c|c|c|c|c|c|}
\hline \multirow{3}{*}{ Final Stage } & \multicolumn{4}{|c|}{ Period } & \multirow{2}{*}{\multicolumn{2}{|c|}{ Total }} \\
\hline & \multicolumn{2}{|c|}{$1997-2006$} & \multicolumn{2}{|c|}{$2007-2016$} & & \\
\hline & $\mathbf{N}$ & $\%$ & $\mathbf{N}$ & $\%$ & $\mathbf{N}$ & $\%$ \\
\hline Absence of tumor & 0 & 0.0 & 2 & 0.2 & 2 & 0.2 \\
\hline IA & 37 & 12.4 & 98 & 14.6 & 135 & 13.9 \\
\hline IB & 29 & 9.7 & 35 & 5.2 & 64 & 6.6 \\
\hline IIA & 12 & 4.0 & 33 & 4.9 & 45 & 4.6 \\
\hline IIB & 24 & 8.0 & 54 & 8.0 & 78 & 8.0 \\
\hline IIIA & 20 & 6.7 & 48 & 7.2 & 68 & 7.0 \\
\hline IIIB & 24 & 8.0 & 73 & 10.9 & 97 & 10.0 \\
\hline IIIC & 53 & 17.8 & 103 & 15.4 & 156 & 16.2 \\
\hline IV & 99 & 33.2 & 224 & 33.4 & 323 & 33.4 \\
\hline Total & 298 & 100.0 & 670 & 100.0 & 968 & 100.0 \\
\hline
\end{tabular}

Table 9. Stage

Chi-square test $\quad \mathrm{X}^{2}=10.779 \quad \mathrm{p}=0.2145$

In our study, we did not notice the general findings regarding the incidences of the two histological types. From 1997 to 2006, there was a predominance of diffuse type, the same occurring in the second period with no statistically significant increase, both in the intestinal type and in the diffuse type. This finding contradicts the expectation in the literature, with a decrease in the incidence of intestinal adenocarcinomas, traditionally related to $H$. pylori infection. In these circumstances we must really question whether this infection is as important as it is intended. Why there was not there any decreases in intestinal adenocarcinoma rates, as we see in other countries? Why, in the past decade, in our series, there were more diffuse than intestinal types, since the opposite occurred in literature? Has our population not changed their habits? Hasn't H. pylori been eradicated as much as necessary? Apparently in several countries, eradication was more comprehensive [22].
As for the different subtypes, that is, signet ring, well and moderately differentiated and poorly differentiated, there was no statistically significant difference, confirming what had already been observed in the two main groups, (intestinal and diffuse).

Regarding global mortality, it is important to emphasize that we do not perform the analysis separately only in operated patients, but from our entire sample, including patients considered inoperable and those operated with curative or even palliative intent. We noticed that the global mortality decreased in the most recent period. Several aspects could be responsible for this decrease, namely: significant decrease in the depths of the tumors diagnosed between 2007 and 2016; improvement in surgical outcomes with lower mortality; greater access to complementary treatments, chemo and radiotherapy, practically nonexistent in the first period. We also remember that there was no 
increase in the rate of resectability, which could have contributed to increased survival.

As already discussed in the previous paragraph, there was a decrease in the depth of the tumors $(\mathrm{T})$ in the period between 2007 and 2016 (Table 7), which indicates that we may be achieving a small improvement in diagnosis, which leaves hope for future prevention campaigns of this so lethal disease. Unfortunately, the same did not occur with $\mathrm{N}$ staging (Table 8), with similar rates of lymph node involvement in the two periods studied. Also in metastatic disease there was no improvement as we had a frightening rate of $30 \%$ (Table 9).

We also did not notice differences in the stage, with no significant epidemiological differences at any stage. In the two decades, there was a high number of patients in advanced stages, with no difference from one decade to another. In comparison, in a Korean study with 5,507 patients, the distribution was as follows: stage IA $(\mathrm{n}=2,383,43.3 \%)$, stage IB $(n=733,13.3 \%)$, stage IIA $(n=424,7.7 \%)$, stage IIIB $(n=375$, $6.8 \%)$, stage IIIC $(\mathrm{n}=197,3.6 \%)$ and stage IV $(\mathrm{n}=224,4.1 \%)$. Ninety three point six percent $(93.6 \%)$ had the same classification if we take into account the eighth edition of AJCC, while $3.5 \%$ of patients had a higher stage and $2.9 \%$ a lower stage [23].

We noticed that the extensions and types of resection were similar in both periods. There was a small increase in proximal neoplasms (U), although there was a decrease in cardiac types II and III neoplasms. This fact itself is already quite interesting, since the world literature also shows an increase in proximal tumors, but with an increase in cardiac cancers, neoplasms possibly related to gastro-esophageal reflux [24]. The weight gain of the Brazilian population seems to have occurred more recently, therefore, we may come to notice the influence of reflux-related neoplasms later. There is a lower percentage of tumors that affect the entire extension of the stomach (LMU and UML), which leads us to think that the diagnoses in our service are occurring more quickly, before the tumor can affect the entire extension of the stomach.

There may also have been an improvement in the population's information, better access to diagnosis, more availability of diagnostic tests or a shorter wait for a surgical intervention, however this was not noticed when we observed that the stages in the two decades were very similar. The lymph node stage $(\mathrm{N})$ did not change in the two decades, allowing two conclusions: first, it was not possible to obtain a proportionally earlier diagnosis, and second, we maintained an adequate level of lymphadenectomy in both periods, the result of the great training of the surgeons in our service, as well as pathologists.

The incidence of metastases (M1) has also not changed and portrays the failure to seek early diagnosis in our service.

\section{References}

1. Crew KD, Neugut AI (2006) Epidemiology of gastric cancer. World J Gastroenterol 12: 354-362. [Crossref]

2. Parkin DM (2004) International variation. Oncogene 23: 6329-6340.

3. Parkin DM, Bray FI, Devesa SS (2001) Cancer burden in the year 2000. The global picture. Eur J Cancer 37 Suppl 8: S4-66. [Crossref]
4. Kelley JR, Duggan JM (2003) Gastric cancer epidemiology and risk factors. J Clin Epidemiol 56: 1-9.

5. Zheng H, Takahashi H, Murai Y, Cui Z, Nomoto K, et al. (2007) Pathobiological characteristics of intestinal and diffuse-type gastric carcinoma in Japan: an immunostaining study on the tissue microarray. Journal of clinical pathol 60: 273-277.

6. Hu B, El Hajj N, Sittler S, Lammert N, Barnes R, et al. (2012) Gastric cancer Classification, histology and application of molecular pathology. J Gastrointest Oncol 3: 251-61.

7. Polkowski W, van Sandick JW, Offerhaus GJ, ten Kate FJ, Mulder J, et al. (1999) Prognostic value of Lauren classification and c-erbB-2 oncogene overexpression in adenocarcinoma of the esophagus and gastroesophageal junction. Ann Surg oncol 6 : 290-297.

8. Laurén P (1965) The Two Histological Main Types of Gastric Carcinoma: Diffuse and So-Called Intestinal-Type Carcinoma. An Attempt at a Histo-Clinical Classification. Acta pathol microbiol Scand 64: 31-49.

9. Caldas C, Carneiro F, Lynch HT, Yokota J, Wiesner GL, et al. (1999) Familial gastric cancer: overview and guidelines for management. J Med Genet 36: 873-880.

10. Kaneko S, Yoshimura T (2001) Time trend analysis of gastric cancer incidence in Japan by histological types, 1975-1989. Br J Cancer 84: 400-405.

11. Parsonnet J, Vandersteen D, Goates J, Sibley RK, Pritikin J, et al. (1991) Helicobacter pylori infection in intestinal- and diffuse-type gastric adenocarcinomas. J Natl Cancer Inst 83: 640-643.

12. Washington $\mathrm{K}(2010) 7$ th edition of the AJCC cancer staging manual: stomach. Annals of surgical oncology 17: 3077-3079.

13. Japanese Gastric Cancer A (2011) Japanese classification of gastric carcinoma: (3rd Edn). Gastric Cancer 14: 101-112.

14. Siewert JR, Stein HJ (1996) Carcinoma of the gastroesophageal junction - classification, pathology and extent of resection. Diseases of the Esophagus 9: 173-182.

15. Mansfield PF (2019) Surgical management of invasive gastric cancer. In: Tanabe KK, Soybel DI, Savarese DMF, Chen W (Eds) UpToDate.

16. Kassab P, Leme PLS (2003) Epidemiologia do câncer gástrico. Rev Assoc Méd Bras 49: $128-128$.

17. Majek O, Krejci D, Pavlik T, Muzik J, Dusek L (2018) Basic epidemiology of oesophageal cancer in the Czech Republic. In: Obermannova R, Lordick F, Petruzelka L (Eds) Multidisciplinary Approach to Oesophageal and Gastric Cancer. (1st Edn) 1: 35 .

18. Torre LA, Islami F, Siegel RL, Ward EM, Jemal A (2017) Global Cancer in Women Burden and Trends. Cancer Epidemiol Biomarkers Prev 26: 444-457

19. Castro OAP, Tagawa ACS, Perea MRF, Vicenzi R, Saab P, et al. (2005) Nutritional Evaluation of Gastric Cancer Patients. In: Annals of the 6th International Gastric Cancer Congress, Yokohama, Japan.

20. Cislo M, Filip AA, Arnold Offerhaus GJ, Cisel B, Rawicz-Pruszynski K, et al. (2018) Distinct molecular subtypes of gastric cancer: from Lauren to molecular pathology. Oncotarget 9: 19427-19442.

21. Correa P (2013) Gastric cancer: overview. Gastroenterol clin of North Am 42: 211-217.

22. Marcus EA, Sachs G, Scott DR (2016) Eradication of Helicobacter pylori Infection. Curr Gastroenterol Rep 18: 33.

23. Kim SG, Seo HS, Lee HH, Song KY, Park CH (2017) Comparison of the Differences in Survival Rates between the 7th and 8th Editions of the AJCC TNM Staging System for Gastric Adenocarcinoma: a Single-Institution Study of 5,507 Patients in Korea. $J$ Gastric Cancer 17: 212-219.

24. Blot WJ, Devesa SS, Kneller RW, Fraumeni JF Jr (1991) Rising incidence of adenocarcinoma of the esophagus and gastric cardia. JAMA 265: 1287-1289. [Crossref]

Copyright: (C2020 Nogueira EP. This is an open-access article distributed under the terms of the Creative Commons Attribution License, which permits unrestricted use, distribution, and reproduction in any medium, provided the original author and source are credited. 